\title{
Development of a Digital Dip Coating System Based Microcontroller
}

\author{
Yohandri*, Khairunnisa, Ramli and Rahadian Zainul \\ Department of Physics, Faculty of Mathematics and Natural Science, Universitas Negeri \\ Padang, Indonesia
}

*Email: yohandri@fmipa.unp.ac.id

\begin{abstract}
Coating techniques are important parts in the development of nano material technology. In this paper, the development of coating technology based on microcontroller using dip coating is presented. Arduino microcontroller is implemented to control the immersion time and the speed of withdrawal of material out of the coating fluid through a stepper motor. In addition, the withdrawal speed can be digitally entered through a keypad with a value range of $0.02 \mathrm{~mm} / \mathrm{s}$ to $10 \mathrm{~mm} / \mathrm{s}$. The experiment results showed the percentage of accuracy and precision of the microcontroller based dip coater was very high. Based on these results, the developed dip coater is satisfied to be used in the development of nanotech materials
\end{abstract}

Keyword: Microcontroller, Digital, Coating, System, Development

\section{Introduction}

Coating technology is a major supporter in the technological advances in nano materials and thin film. Several applications of thin film and nano material can be found in many areas such as the manufacture of components, decorations, jewelry and as a metal coating material to avoid the corrosion [1,2]. In electronics field, electronic components are developing in line with the developing of thin film technology. There are several methods that can be implemented in making thin film including electroplating, painting, spin coating, and dip coating. Among these methods, the dip coating method has several advantages including the larger size of the coating media, faster manufacturing process, and less coating material.

Dip coating is a coating method by immersing material into a solution for a certain time and then withdraw the material from the container. In dip coating techniques, several parameters become very important to control. Among these parameters are the dyeing speed, immersing time, and speed of withdrawal of the material from the coating agent. Withdrawal speed is an important variable in this technique, because it will affect the thickness of the formed layer. Giving different speeds will produce different layer thickness [3].

In previous research [4], a coater system has been developed with two discrete withdrawal speed, namely $4.22 \mathrm{~cm} / \mathrm{s}$ and $9.07 \mathrm{~cm} / \mathrm{s}$. With this speed option, only two types of material can be produced and cannot be varied according to the user's wishes. In other studies [5], low cost dip coaters have been developed for thin films, however, speed control is done 
manually and has not been digitally constructed. For this reason, this research will develop a microcontroller-based dip coater system that can adjust the speed of dyeing, immersing time and speed of withdrawal digitally according to user needs

Microcontroller-based instrument present many advantages including low cost, easy to repair, data can be recorded digitally and can be programmed according to the design of the system. On the other hand, microcontroller easy to customized and programmed for various application [68]. In the next section, the system of the dip coater will be described. In section three, the results and discussion will be presented

\section{Dip Coating System}

Microcontroller-based dip coater systems are built using several components, namely lead screws, stepper motors, Arduino microcontrollers and power supply. Stepper motor serves to rotate the lead screw which will make the coating arm move downward or upward direction. The microcontroller regulates the speed of the rotating stepper which will determine the speed of the dipping arm when entering the liquid or withdraw of the coating liquid. The Design of microcontroller-based dip coater is presented in Fig. 1.

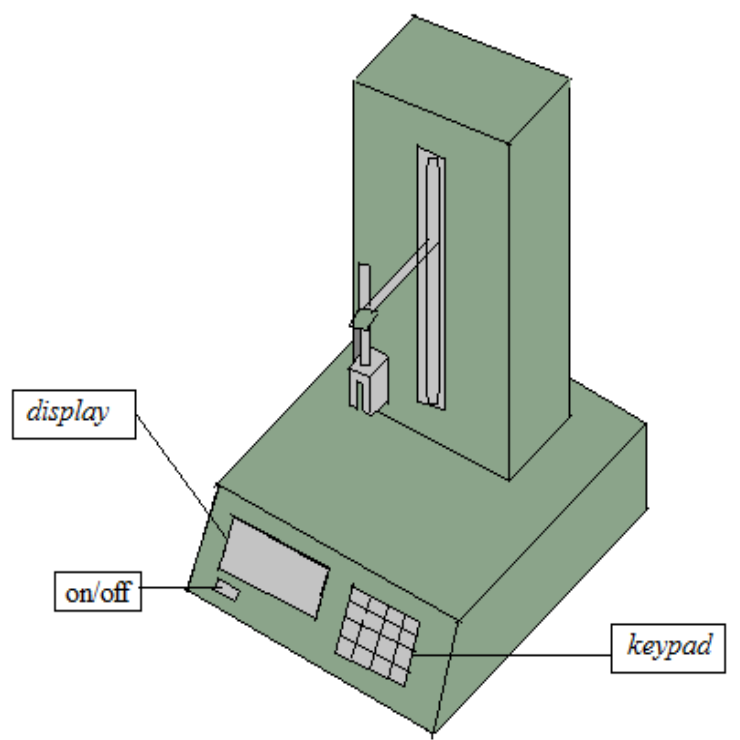

Fig. 1. Design of microcontroller-based dip coater

Microcontroller-based Dip coater consists of a Stepper Motor, Arduino, Power Supply, keypad and LCD. The block diagram of this system is given in Fig. 2. In this block diagram the keypad is used to input the speed and time values. The speed value input will be displayed on the LCD. Controlling the speed and direction of movement of the stepper motor will be controlled through a driver. The stepper motor controller circuit consists of Arduino, driver and stepper motor (Fig. 3). Through the settings in the driver, stepper movements can be more precise with micro step movements. 


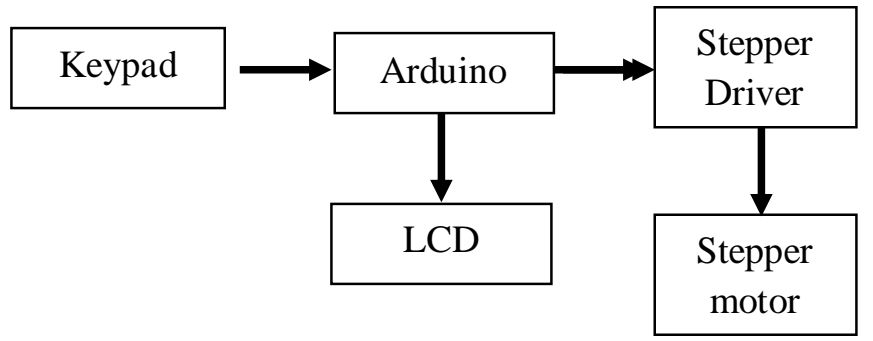

Fig. 2. Block Diagram of microcontroller-based dip coater

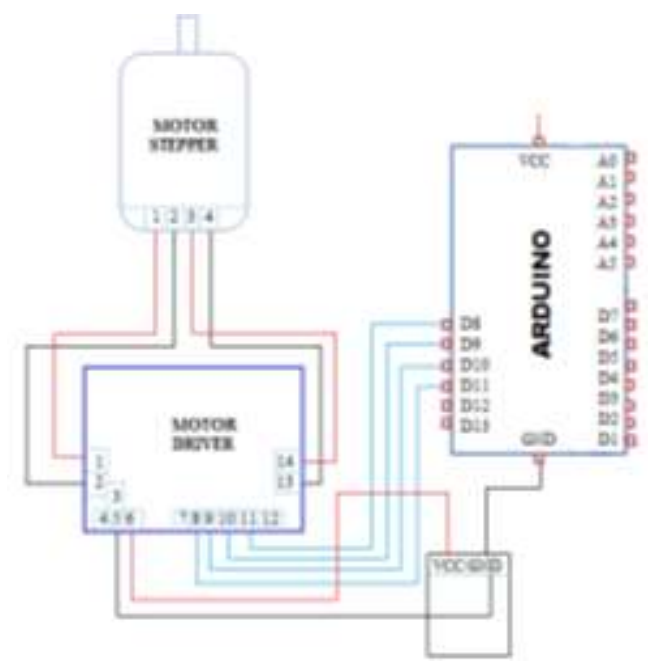

Fig. 3. Scheme of stepper motor controller

To operate a dip coater system, input in the form of down and up speed and immersion time are entered through the keypad. This input data will be translated by a microcontroller in the form of delay which is used to determine the stepper motor rotation speed. Simply put in the flow of Arduino programs shown in Fig. 4. In this program, dying and withdraw speed can be entered freely through the keypad from $0.02 \mathrm{~mm} / \mathrm{s}$ to $10 \mathrm{~mm} / \mathrm{s}$. The movement of the stepper motor up and down direction is limited by a switches installed at the bottom and the top. At the bottom of the stepper movement will stop if the limit switch has been pressed or the subtrate has been immersed perfectly. When the immersion time has run out, the stepper motor will pull out the substrate from coating liquid at a predetermined speed. 

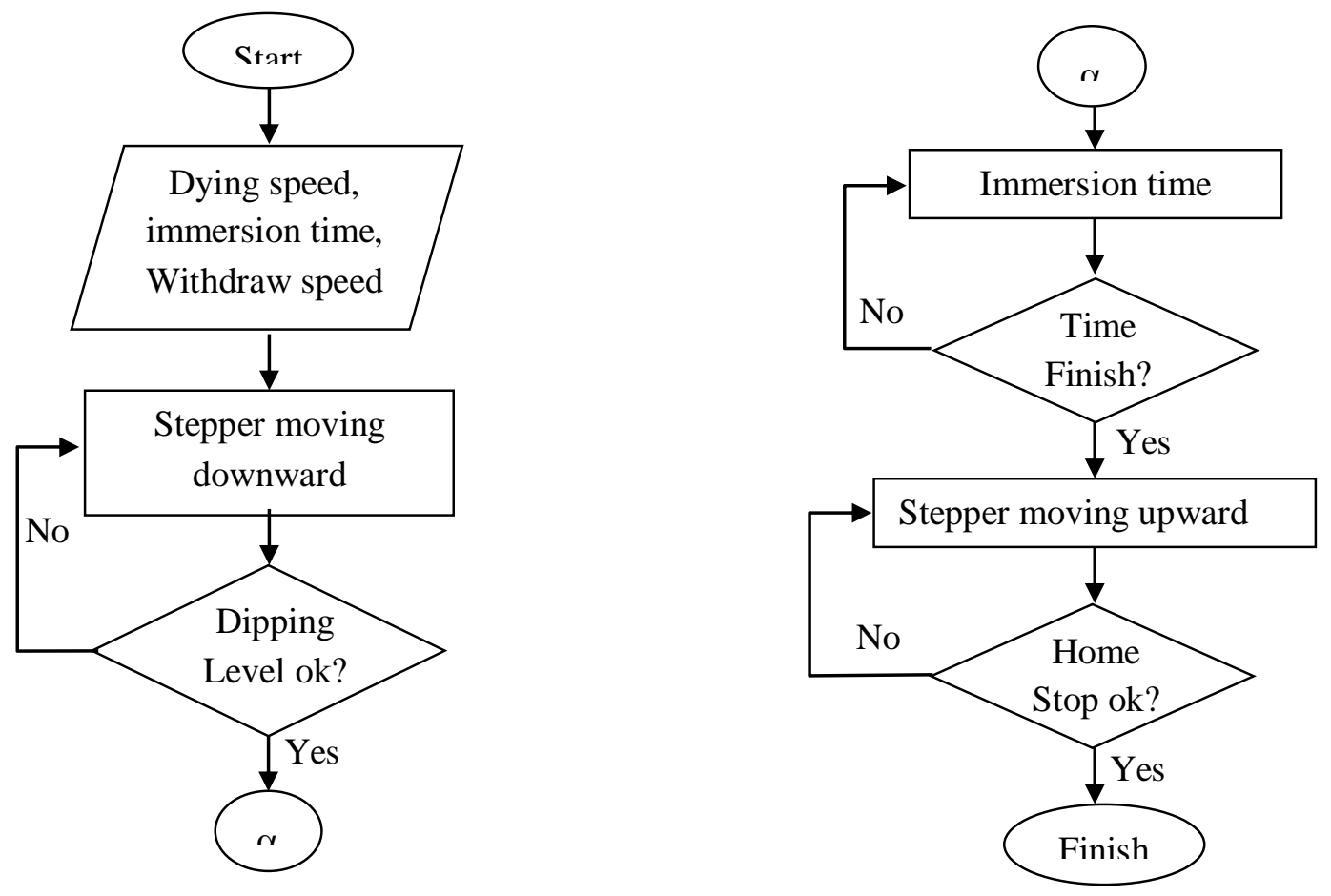

Fig. 4. Flowchart of microcontroller-based dip coater

\section{Results and Discussion}

In this session, the development of the system (hardware) and characterization of the system will be presented. Fig. 5 photographs of the system.

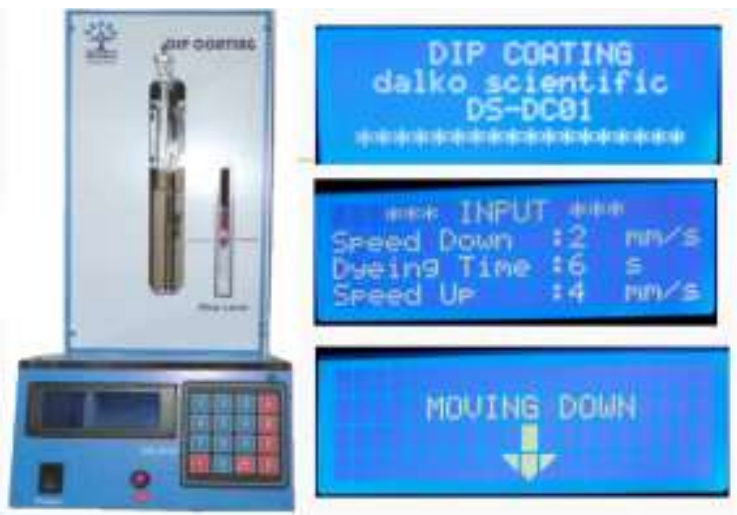

Fig. 5. System (hardware) of dip coater

Characterization of the system is done to determine the performance of the system. The relationship between the delay time and the period output of the microcontroller signal that sent to the stepper motor driver is plotted in Fig. 6. Moreover, the effect of the delay time to the speed 
of the stepper motor also investigated as shown in Fig. 7. Measured accuracy of the system in controlling the stepper motor speed is presented in Fig. 8. The speed of the dip coating system is obtained by giving intervals on the thread and calculating the time taken along the interval, it will get the speed produced by the dip coating system. In this graph, the controlled speed of system and measured speed by a standard instrument (Tachometer) is compared.

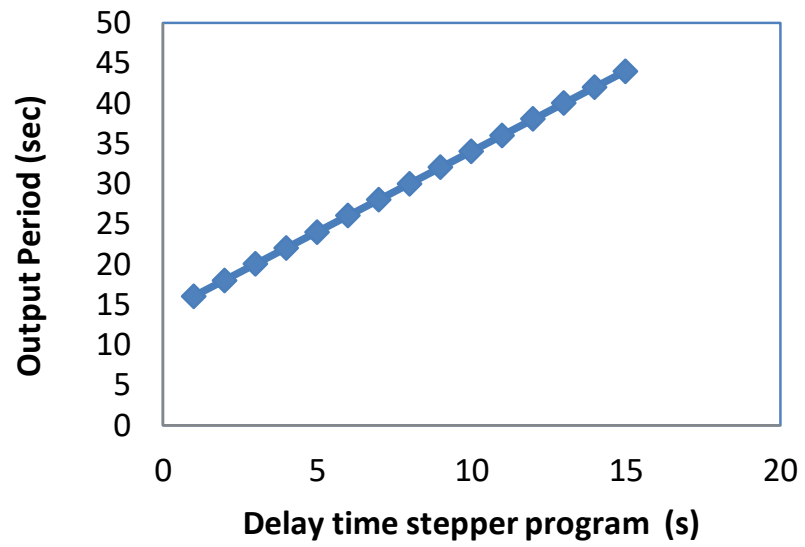

Fig. 6. The relationship between the delay time and the period output of the microcontroller signal that sent to the stepper motor driver

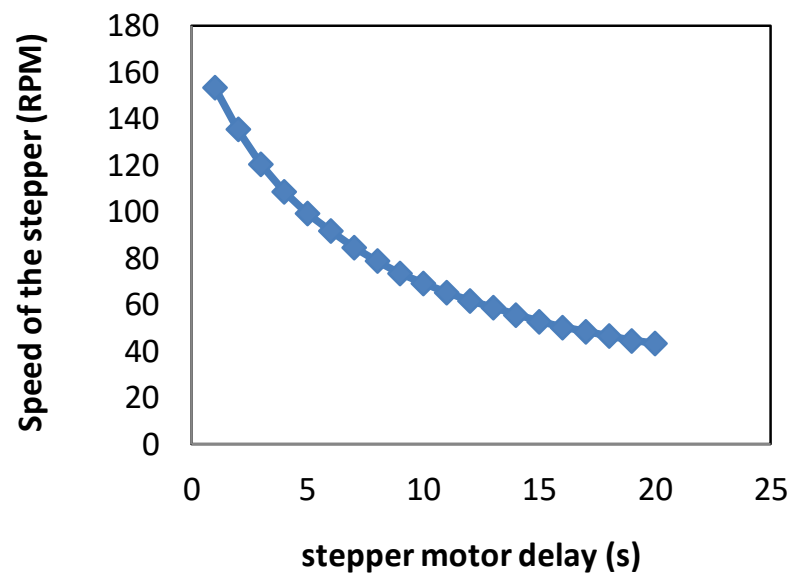

Fig. 7. The effect of the delay time to the speed of the stepper motor 


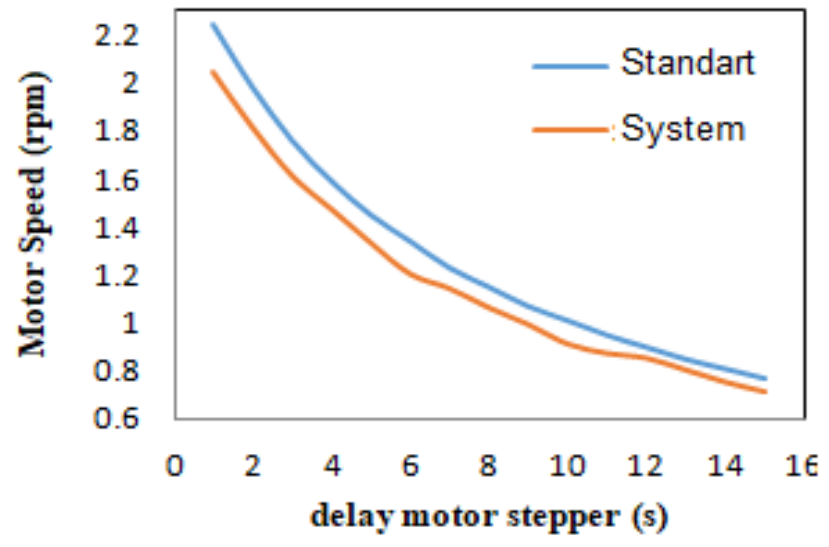

Fig. 8. Measured accuracy of the system in controlling the stepper motor speed

As shown in the graph in Fig. 8, there are slightly differences between the measurement results of the standard measuring instrument and the dip coating system at speed measurements. This inaccuracy comes from the load on the device that affects the speed of the system. The accuracy of controlling the system is $96.57 \%$. The maximum error for speed reading occurs at measurements when the stepper motor delay is $6 \mu \mathrm{s}$.

The dip coating system has been successfully tested for deposition of the $\mathrm{TiO}_{2}$ film on ceramic substrates. The diffraction pattern of sample is shown in Fig 9. The XRD pattern agrees with the JCPDS card no. 01-075-2552. Fig.9 show the typical diffraction patterns of $\mathrm{TiO}_{2}$ films with textured rutile, anatase and mixture. Strong diffraction peaks at $27^{\circ}$ indicating $\mathrm{TiO}_{2}$ in the rutile phase agrees with other literature [11], where the $\mathrm{TiO}_{2}$ film was grown by rf magnetron sputtering apparatus.

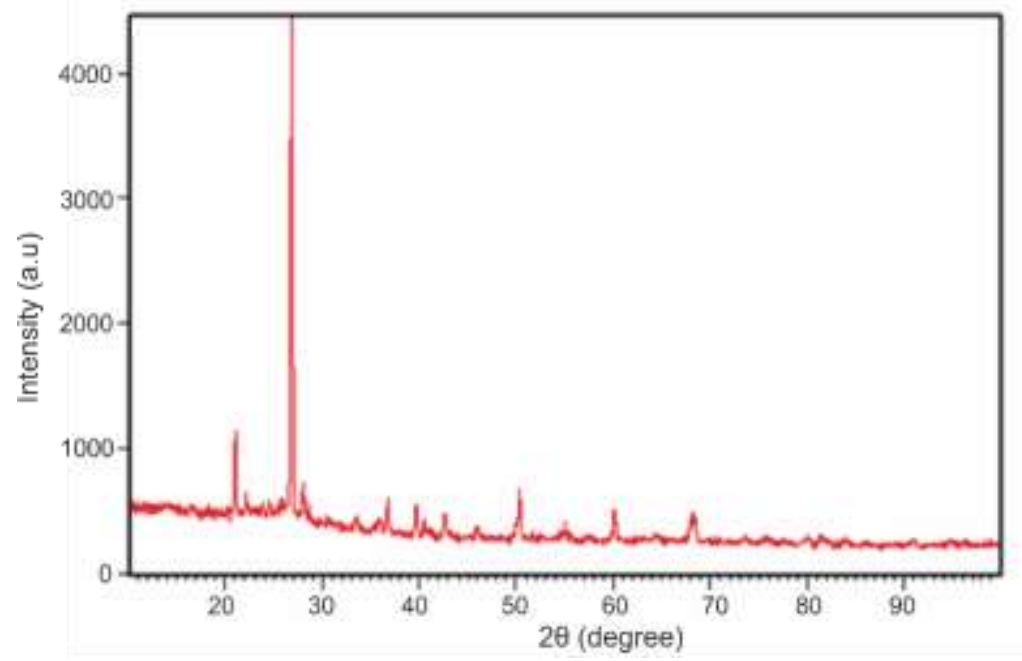

Fig. 9. The XRD pattern of the coating TiO2 on Ceramic 


\section{Conclusion}

In this study a microcontroller-based dip coater system was designed and developed. The microcontroller-based dip coater can be operated precisely with minimum of speed $0.02 \mathrm{~mm} / \mathrm{s}$ and maximum of speed $10 \mathrm{~mm} / \mathrm{s}$. As compares to the standard instrument, the accuracy of controlling the system is $96.57 \%$. This measured result show the developed dip coater can be operated in nano material technology or thin film fabrication.

\section{Acknowledgement}

This research was supported by Ministry of Research, Technology and Higher Education, Indonesia. This work under Applied Research Grant (Penelitian Terapan) with grant number 466/UN35.13/LT/2019

\section{References}

[1] David Loza, Victor Hugo Guerrero and Reza Dabirian, Construction of low cost spin and dip coaters for thin film deposition using open source technology, Revista de Fisica, No. 49, December 2014.

[2] Edgar B.Gutoff and Edward D.Cohen, Chapter 13 - Water- and solvent-based coating technology, Multilayer Flexible Packaging, Plastics Design Library, 2010, Pages 163184, https://doi.org/10.1016/B978-0-8155-2021-4.10013-9

[3] K. Aggoun, L. Chaal, J. Creus, R. Sabot, B. Saidani, M. Jeannin, Marine corrosion resistance of $\mathrm{CeO} 2 / \mathrm{Mg}(\mathrm{OH}) 2$ mixed coating on a low alloyed steel, Surface and Coatings Technology,Volume 372, 2019, Pages $\quad 410-421$ https://doi.org/10.1016/j.surfcoat.2019.05.053

[4] T Frey, M Kögel, Tarnish protection of silver jewels by plasmapolymer coatings, Surface and Coatings Technology, Volumes 174-175, 2003, Pages 902-904 https://doi.org/10.1016/S0257-8972(03)00713-8

[5] Ihsan N, Yulkifli and Yohandri, Development of Speed Measurement System for Pencak Silat Kick Based on Sensor Technology. IOP Conference Series: Materials Science and Engineering, Volume 180, Number 1, 2017

[6] K.Aggoun, L.Chaal, J.Creus, R.Sabot, B.Saidani and M.Jeannin, Marine corrosion resistance of $\mathrm{CeO} 2 / \mathrm{Mg}(\mathrm{OH}) 2$ mixed coating on a low alloyed steel, Surface and Coatings Technology,

[7] Miao L, Jin P, Kaneko K, Terai A, Nabatova-Gabain N, Tanemura S, Preparation and characterization of polycrystalline anatase and rutile $\mathrm{TiO}_{2}$ thin films by rf magnetron sputtering, Applied Surface Science 212-213 (2003) 255-263

[8] T. Frey and M. Kögel Tarnish protection of silver jewels by plasmapolymer coatings, Surface and Coatings Technology, Volumes 174-175, September-October 2003, Pages 902-904.

[9] Yayah Kuriah, Iwan Sugihartono, Studi Deposisi Lapisan Tipis Zno Menggunakan Teknik Dip-Coating, Wahana Fisika, Journal Fisika Dan Terapannya, Vol 3, No 2 (2018), 
[10] Yohandri, Mairizwan and Akmam, "Development of a Digital Resistivity Meter Based on Microcontroller," TENCON 2018 - 2018 IEEE Region 10 Conference, Jeju, Korea (South), 2018, pp. 0551-0554. doi: 10.1109/TENCON.2018.8650464

[11] Yulkifli, Yohandri and Kurniati R, "Development of digital viscometer based on sensor technology and microcontroller", Journal of Physics: Conference Series, Volume 1040, 2018 